\title{
A Pathway for Sustainable Conversion of Sunlight to Hydrogen using Proposed Compact CPV System
}

\author{
Muhammad Burhan ${ }^{1}$, Muhammad Wakil Shahzad ${ }^{1}$, Oh Seung Jin ${ }^{1}$, Ng Kim Choon ${ }^{1}$ \\ ${ }^{1}$ Water Desalination and Reuse Centre, King Abdullah University of Science \& Technology, \\ Saudi Arabia. \\ Email: muhammad.burhan@kaust.edu.sa ; muhammad.shahzad@kaust.edu.sa ; \\ seungjin.oh@kaust.edu.sa ; kimchoon.ng@kaust.edu.sa
}

\begin{abstract}
Solar energy being intermittent in nature, can provide a sustainable, steady and high density energy source when converted into electrolytic hydrogen. However, in current photovoltaic market trend with $99 \%$ conventional single junction PV panels, this cannot be achieved efficiently and economically. The advent of the multi-junction solar cells (MJCs), with cell-efficiency exceeding $46 \%$, has yet to receive wide spread acceptance in the current PV market in form of concentrated photovoltaic (CPV) system, because of its system design complexity, limiting its application scope and customers. The objective of this paper is to develop a low cost compact CPV system that will not only eliminate its application and installation related restrictions but it is also introducing a highly efficient and sustainable photovoltaic system for common consumer, to convert intermittent sunlight into green hydrogen. The developed CPV system negates the common conviction by showing two times more power output than the flat plate PV, in tropical region. In addition, sunlight to hydrogen conversion efficiency of $18 \%$ is recorded for CPV, which is two times higher than alone electricity production efficiency of flat plate PV.
\end{abstract}

Keywords: Hydrogen, CPV, Solar, Concentrated Photovoltaic, Energy Storage

\section{Introduction}

In order to fulfill the global energy needs, if the current trend of relying on the fossil fuels persists then the global warming situation will put environment sustainability in great risk [1-5]. Although, the measures have been taken to reduce the carbon content in the atmosphere [6-8], but not enough to mitigate the risk unless a shift towards sustainable energy sources occurs [9]. For sustainable energy source, it must be readily available all the time [10]. However, renewable energy sources like solar and wind are not suitable to be used as primary energy supply, due to their intermittent nature [11-13]. Hydrogen is considered as a sustainable energy carrier to meet the future global energy needs, due to its higher energy density and portability like fossil fuels [14-16], only if it is produced by renewable energy means. In addition, the emission in case of hydrogen utilization is water [17]. 
Solar energy has the highest energy potential among all of the energy resources [18, 19]. However, due to its intermittent nature and low energy density, there is a need to convert it into high grade energy, to be used as primary energy source $[\mathbf{2 0 , 2 1 ]}$. The conventional electrochemical energy storage method i.e. battery, is the solution for solar intermittency only for small scale and short term applications [22-24]. Sunlight to hydrogen conversion provides a sustainable primary energy option if achieved efficiently and economically [25, 26].

40

Currently, almost entire photovoltaic marker is dominated by conventional single junction photovoltaic (PV) panels i.e. monocrystalline, polycrystalline and thin film based solar cells offering lower efficiency [27-30]. Although such cells have a theoretical efficiency limit of $31 \%$, the actual long term power output rating is merely less than $8 \%$ [31]. Therefore, for a typical 68$70 \%$ [32] efficient electrolyser, the less efficient single junction PV does not provide a sustainable solution for hydrogen production. However, third generation multi-junction solar cells (MJCs), with cell efficiency exceeding 46\% [33] and system efficiency 25-29\% [34] as concentrated photovoltaic (CPV) [35], have yet to receive wide spread acceptance in the current PV market because of their system design complexity and application constraints [36]. The conventional gigantic design of CPV systems limits their application scope for only open desert regions [37], with less customers and market share, despite highest efficiency. The potential of small scale photovoltaic system for rooftop application can be estimated as 40-50\% of total PV installations [38] and many rebate schemes were given in US and Japan for rooftop PV installation due to its importance, but no such compact system design is offered yet for CPV technology [39]. However, it is not that simple to have compact CPV system design as it requires more number of tracking units for the same capacity of the CPV field, thereby increasing overall cost and control hardware requirement of the entire CPV field. In addition, CPV system requires very high solar tracking accuracy of 0.1-0.3 degree, unlike PV [40]. In literature, many studies are available which discuss the tracking requirement of conventional $\mathrm{PV}$, which varies from single axis to two axis control with feedback [41-44]. But such PV tracking methodologies cannot be adopted for CPV due to their poor tracking accuracy. Therefore, such high accuracy can be achieved through hybrid tracking technique with both optical and astronomical tracking methods. The astronomical tracking is a well-established technique based upon the solar geometry. However, alone, it cannot ensure high tracking accuracy due to its open loop operation which is susceptible to errors under wind turbulence and mechanical backlash. Therefore, real-time feedback about actual solar position is very important to ensure tracking accuracy, and it is obtained from optically designed solar tracking sensors. The solar tracking sensor developed for PV, based upon tilted wedge, rod and collimator based shadow concepts [45], does not offer high accuracy which is in the range of $25^{\circ} \mathrm{C}$ [46]. However, the only commercially available solar tracking sensor is based upon high cost position sensitive diode (PSD) [47, 48]. Such high cost unit does not appear to be economical choice for compact CPV design due to increased number of units.

The objective of this paper is to introduce a compact but low cost CPV system to be available commonly in photovoltaic market as a highly efficient photovoltaic technology with highest power 
density and smaller footprint. The compact CPV design will boost its market share and customers by eliminating its installation related restrictions, through proposed master-slave configuration and twin lens collimator based solar tracking sensor. In addition, as sustainable and steady power source, a compact CPV-Hydrogen system will be developed, which will not only eliminate its operational limitation of intermittency but it will further increase its application scope and market potential by offering Green Hydrogen and byproduct Oxygen; one of the biggest industrial need. From system performance evaluation, sunlight to hydrogen production efficiency of $18 \%$ was recorded which is 2 times the electrical efficiency of flat plate PV. The study also highlights the two times higher performance potential of CPV than flat plate PV, in tropical and urban region as CPV is considered only suitable to be operated in desert regions with clear sky conditions. For the first time, in this paper, CPV system has been presented as a feasible and sustainable solar energy system, by not only providing its competitive design against conventional PV systems but its detailed performance analysis is provided for hydrogen production as solar energy storage or fuel production, especially in the tropical region which is falsely considered as non-feasible for CPV operation.

\section{Compact CPV Field Configuration}

Figure 1 shows the simple schematic of master-slave field configuration for compact CPV system field, to reduce the overall control hardware requirement and associated cost despite increased number of tracking units needed for such approach. In the proposed master-slave configuration, one master tracker is equipped with all of the expensive and sophisticated tracking modules, needed to get required solar tracking data. Such data, after sorting and filtering, is then sent to rest of the slave trackers in the CPV field, using wireless Zigbee transceivers with radio signal communication. Rest all of the slave trackers are only equipped with controller and motor drivers, which is the minimum control hardware requirement for solar tracking unit. However, remaining required tracking modules, supplied to master tacker, are replace with single Zigbee transceiver, resulting in simple configuration of slave trackers with reduced system cost. The main importance of such wireless communication is that CPV field of slave trackers can be designed at the rooftop of multiple building, irrespective of their height.

Zigbee network utilizes low communication protocol using radio frequency, in which the center device (master) creates a network and rest of the zigbee devices (slaves) join the same network for communicating with central device. The central zigbee device is called as coordinator and represented by ' $\mathrm{C}$ '. However, rest of the slave zigbee devices are called as router or end device and represented by ' $\mathrm{R}$ ' or 'ED' respectively. The router or end devices are named based upon their communication patterns as router can have a two way communication while end devices can only accept the instruction, without any feedback. In any zigbee network, the slave units in the outer most ring acts as 'ED' while remaining slave zigbee devices act as 'R'. Following equations (1) and (2) are used to map the slave tracker positions, as explained in [49], and controlled through Zigbee communication and modules. 


$$
\text { Cskip }=1+C_{m}\left(L_{m}-d-1\right) \quad \text { if } R_{m}=1, \quad \text { for }, d<L_{m}
$$

$$
\text { Cskip }=\frac{1+C_{m}-R_{m}-\left(C_{m} R_{m}^{\left(L_{m}-d-1\right)}\right)}{1-R_{m}}, \text { otherwise, for, } d<L_{m}
$$

\section{Twin Lens Collimator based Solar Tracking Sensor}

A simple schematic of low cost but highly accurate solar tracking sensor is proposed in Fig. 2. It is based upon twin lens collimator and the photo-sensors array. The collimator concentrates and collimates the incoming solar radiations into a bright spot at the center of the photo-sensor array. It must also be noted that the purpose of using concentrated beam is to operate photo-sensors in binary operation and to eliminate their non-linear response against illumination, as the intensity of incident beam is higher than their saturation limit.

For operation, this solar tracking sensor is aligned with the tracker such that when the tracker is accurately facing the sun, the concentrated bright spot is in the center of photo-sensor array. During tracking error, the incoming solar radiations do not remain aligned with the collimator axis and as a result, the concentrated bright spot translates from the center of photo-sensor array. When the tracking error exceeds from its acceptable limit, the bright spot hits any of the photo-sensor in the array, giving high output signal. Based upon the position of activated photo-sensor and the tracking algorithm programmed, the solar tracker is adjusted such that to bring concentrated bright spot back in the center of photo-sensor array. The distance between lenses ' $S$ ' and the collimated beam thickness are the two design factors of twin lens collimator, given by equations (3) and (4), respectively. The parameters ' $f_{c n}$ ' and ' $f_{c x}$ ' represents the focal lengths of the concave and convex lenses, respectively.

$$
S=f_{c x}+\left(-f_{c n}\right)
$$

$$
b_{t}=\frac{D_{c x}}{f_{c x}} \bullet f_{c n}
$$

The point of interest, regarding performance of solar tracking sensor for CPV, is its sensitivity i.e. shift in the linear position of concentrated bright spot for per degree angular deviation in the incoming rays. High sensitivity reflects detection capability of sensor for even smaller errors, which is essential for CPV solar tracking. The optical performance of designed solar tracking sensor was analyzed in Tracepro software with parameters $f_{c x}=80 \mathrm{~mm}, D_{c x}=20 \mathrm{~mm}$ and $f_{c n}=-12 \mathrm{~mm}$. The resultant performance graphs from ray tracing simulations are shown in Fig. 2. It can be seen that the sensor has sensitivity of 7.45 , given by the slope of the graph. It depicts that with $1^{\circ}$ deviation in the incident radiations, there is $7.45^{\circ}$ deviation in the collimated beam. The other graph shows the linear translation of bright spot against the incident ray deviation, for different gaps 
142 between photo-sensor array and concave lens. Although, the bigger gap reflects higher sensitivity 143 but it increases the overall size of the sensor.

\section{Prototype of Compact CPV with Hydrogen system}

Based upon the proposed master-slave configuration and the twin lens collimator centered solar tracking sensor design, a prototype of the CPV field with compact CPV system, hydrogen production/compression and storage unit, is developed to analyze system performance and operation for rooftop application, as shown in Fig. 3. One of the unit acts as master and the remaining three units act as slaves, using Zigbee transceivers. All of the solar tracking units are loaded with hybrid tracking algorithm which is explained at the end of this section in Fig. 4. The developed hybrid algorithm employs both astronomical/passive and active/optical tracking methods. The passive/astronomical tracking methods is based upon the solar geometry model that defines the solar position coordinates based upon the information of latitude, longitude, date and time of current location. Such information required for the astronomical tracking methods, is obtained from sophisticated electronic modules i.e. GPS and RTC (real time clock). However, in proposed master salve configuration of compact CPV system, only master tracker is equipped with such modules, and sending the required information to the slave trackers. The control box of master solar tracker is based upon microcontroller, loaded with hybrid tracking algorithm, with required modules, Zigbee transceivers and the motor drivers. However, the control box of tracking unit only consists of microcontroller, Zigbee transceivers and the motor drivers. Such passive tracking method works as open loop technique without any feedback. However, the mechanical drive assembly of the solar tracker in prone to backlash as it consists of two worm wheel and gear assemblies. Therefore, to ensure tracking accuracy, all of the CPV units are equipped with developed twin lens collimator centered solar tracking sensor that provides real time feedback regarding solar position. Based upon the master slave configuration and low cost solar feedback sensor, the overall cost of the compact CPV system can be reduced. The mechanical supporting structure of these solar trackers supports the CPV module, to track the solar position during its operation in horizontal (azimuth) and vertical (zenith) directions. The CPV module is based upon solar concentrating assembly and the triple junction $\mathrm{InGaP} / \mathrm{InGaAs} / \mathrm{Ge}$ solar cell. The concentrating assembly is based upon solar concentrator and the secondary optics as homogenizer. The solar concentrator concentrates solar radiations onto the homogenizer which further guides and uniformly distributes it over the cell area, which is placed at the outlet aperture of the homogenizer. Four different concentrating assemblies based upon Fresnel lens and the parabolic reflector, were designed and fabricated to study their performance, which not under scope of this study. However, the electricity output from the MJC solar cells is supplied to hydrogen system. It is important to mention here that although, the solar tracker is based upon hybrid tracking which can correct the small tracking errors which can rise due to mechanical backlash. However, there is a chance of big disturbance in the tracker position in case of heavy winds and such error cannot be corrected due to limited view angle of solar feedback sensor. 
The hydrogen system consists of hydrogen production and compression/storage units. The power output from all of the CPV units is supplied to the Hydrogen production unit, based upon a stack of PEM electrolyser, through MPPT (maximum power point tracking) device or DC/DC converter. The solar cell has its own maximum power point at certain conditions while electrolyser has its own current-voltage (I-V) characteristics. Therefore, for optimum performance, they cannot be connected directly but through intermediate power balancing device i.e. MPPT or DC/DC converter. The flow schematic of developed compact CPV field, with hydrogen system is shown in Fig 3(b). The hydrogen/oxygen gases produced by the electrolyzer are temporarily stored over water to measure their quantity, in terms of change in the water level as measured through level sensor which is measured with $\pm 1.5 \%$ accuracy. When the water level reaches to minimum, the hydrogen/oxygen compressor then sucks the stored gases from these water tanks, restoring the water level. The comoressed gases are then stored separately in the gas cylinders. The performance parameters from every component of the system are recorded through central data logging unit. The central data logging and control system manages the overall operation of the whole system through LabVIEW programming. The solar input data is recorded through pyranometer and Pyrheliometer with calibration accuracy of $\pm 1 \%$.

\subsection{Hybrid Tracking Algorithm}

For operation and control of the two axis solar tracker, the hybrid tracking algorithm is developed using C-programming through CodevisionAVR compiler and implemented through Atmega2560 based microcontroller. The overall structure and implementation of hybrid tracking algorithm is shown in Fig. 4. The astronomical tracking algorithm acts as a primary tracking method, which is implemented through already developed solar geometry model [50]. Azimuth and Zenith are two solar tracking angles which define the solar position in horizontal and vertical plane, with reference to south plane and horizontal plane respectively. These two angle i.e. Azimuth $\theta_{\mathrm{a}}$ and Zenith $\theta_{\mathrm{z}}$, are calculated by using equation (5) and (6).

If $\omega>0$,

$$
\theta_{a}=360-\left[90+\cos ^{-1} \frac{\sin \delta-\sin \left(90-\theta_{z}\right) \sin \phi}{\cos \left(90-\theta_{z}\right) \cos \phi}\right]
$$

If $\omega<0$,

and

$$
\theta_{a}=90+\cos ^{-1} \frac{\sin \delta-\sin \left(90-\theta_{z}\right) \sin \phi}{\cos \left(90-\theta_{z}\right) \cos \phi}
$$

$$
\theta_{z}=\cos ^{-1}\{\sin \phi \sin \delta+\cos \phi \cos \delta \cos \omega\}
$$


211 Where $\phi, \omega$ and $\delta$ are latitude, hour and declination angles respectively. When the difference 212 between the calculated solar position and the actual position of tracker is within the required tracking accuracy, the tracker stops otherwise it is moved accordingly. In order to ensure the solar tracking accuracy, after completion of primary method of astronomical tracking, the realtime feedback regarding actual position of sun is received from developed solar tracking sensor and analyzed through Atmega2560 microcontroller. If all of the feedback signals give low values then it depicts accurate solar tracking within required error limit, otherwise the tracker is moved in accordance with the high feedback signal from certain photo-sensor. This overall loop is then repeated during whole day operation till sunset, when tracker come to its initial position and again resumes its operation after sunrise.

\section{Testing Methodology}

In order to analyze the performance of the hydrogen with concentrated photovoltaic (CPV) system and its potential comparison with conventional PV, it is important to understand the energy potential of hydrogen. Eq. (7) shows the simple chemical reaction of hydrogen and oxygen in fuel cell. For such exothermic reaction, $237.2 \mathrm{KJ} \mathrm{mol}^{-1}$ of energy is released as electricity and $48.6 \mathrm{KJ}$ $\mathrm{mol}^{-1}$ of energy is released as heat. The sum of these two energies is equivalent to HHV of hydrogen i.e. $285.8 \mathrm{KJ} \mathrm{mol}^{-1}$. This is the maximum energy output per mol of hydrogen.

$$
\mathrm{H}_{2}+1 / 2 \mathrm{O}_{2}=\mathrm{H}_{2} \mathrm{O}_{\text {(liquid) }}+237.2 \mathrm{~kJ} \mathrm{~mol}^{-1} \text { (Electricity) }+48.6 \mathrm{~kJ} \mathrm{~mol}^{-1} \text { (Heat) }
$$

From electrolytic point of view, the energy is needed to be supplied to split the water molecule into its constituents of hydrogen and oxygen, but such energy is in the form of electricity. The supplied energy at least must be same as the total energy released during formation of water molecule [51] i.e. $285.8 \mathrm{KJ} \mathrm{mol}^{-1}$. The Gibbs free energy of such reaction is $237.2 \mathrm{~kJ} \mathrm{~mol}^{-1}$ which is equivalent to $1.23 \mathrm{~V}$; the minimum voltage needed to split a water molecule [52], which is considered as the standard anode potential. But such energy is not accounting the remaining 48.6 $\mathrm{kJ} \mathrm{mol}^{-1}$ which was released as heat. Therefore, such remaining energy is also needed to be considered and supplied in form of electricity if water molecule undergoes electrolysis reaction. By considering the Gibbs free energy, the efficiency of electrolysis (output over input) is only depending upon the voltage of water splitting i.e. the operating voltage of electrolyser, Eq. (8).

$$
\eta_{E L}=\frac{\dot{n}_{E, H 2} 237200}{I_{E} \cdot U_{E}}=\frac{\eta_{E F} 1.23 N_{E C}}{U_{E}}
$$

Therefore, the overall solar to hydrogen efficiency for CPV systems, based upon the input energy in form of CPV electricity, from solar energy, and output energy in form of hydrogen, is given by Eq. (9). 
$\eta_{S T H}=\frac{P_{\text {out }}}{P_{\text {in,solar }}} \frac{\left(\dot{n}_{E, H 2} 237200\right)}{\left(\frac{P_{C P V}}{\eta_{C P V}}\right)}=\frac{\eta_{E F} I_{E} 1.23 N_{E C}}{\left(\frac{P_{E}}{\eta_{C P V}}\right)}=\frac{\eta_{E F} I_{E} 1.23 N_{E C}}{\left(\frac{U_{E} I_{E}}{\eta_{C P V}}\right)}=\eta_{C P V} \frac{\eta_{E F} 1.23 N_{E C}}{U_{E}}=\eta_{C P V} \eta_{E L}$

244 245

246

247

248

249

250

251

252

258 254 255

It must be noted that the power produced by the CPV is same as the power consumed by the electrolyser i.e. $\mathrm{P}_{\mathrm{CPV}}=\mathrm{P}_{\mathrm{E}}$.

In order to theoretically analyze and simulate the power output of CPV, the performance model is based upon the single diode model for solar cell under concentration, Eq. (10). By invoking $d P_{C} / d V_{C}=0$ for maximum power point of solar cell, the power output from single CPV cell is given by Eq. (11), if the temperature characteristics of triple junction InGaP/InGaAs/Ge solar cell, as given in table 1 , and the area concentration ratio are known.

$$
\begin{gathered}
P_{C}=I_{C} V_{C}=V_{C}\left[I_{o}\left\{\exp \left(\frac{q V_{C}}{n k T_{C}}\right)-1\right\}-I_{S C}\right] \quad \text { where }\left\{\begin{array}{l}
I_{o}=\frac{I_{S C}}{\left[\exp \left(\frac{q V_{O C}}{n k T_{C}}\right)-1\right]} \\
w h e n V_{C}=V_{O C} \text { and } I_{C}=0
\end{array}\right. \\
P_{m p p t}=\left(I_{0}\left\{\exp \left(\frac{q V_{\text {mppt }}}{n k T_{C}}\right)-1\right\}-I_{S C}\right) \times\left(V_{O C}-\frac{n k T_{C}}{q} \ln \left\{1+\frac{q V_{\text {mppt }}}{n k T_{C}}\right\}\right) \quad \text { where }\left\{\begin{array}{l}
V_{O C}\left(T_{C}, C_{C}\right)=\left[V_{o C}\left(a t 25^{\circ} C\right)\right]_{C}+\left(T_{C}-25\right)\left[\frac{d V_{O C}}{d T_{C}}\right]_{C} \\
I_{S C}\left(T_{C}, C_{C}\right)=\left[I_{S C}\left(a t 25^{\circ} C\right)\right]_{C}+\left(T_{C}-25\right)\left[\frac{d I_{S C}}{d T_{C}}\right]_{C} \\
C_{C}=I_{b} \times \frac{A_{c o n}}{A_{C}} \times \eta_{O P} \\
V_{O C}\left(a t 25^{\circ} C\right)=0.0755 \ln \left(C_{C}\right)+2.5526 \\
I_{S C}\left(a t 25^{\circ} C\right)=4.3804 C_{C}
\end{array}\right.
\end{gathered}
$$

In order to demonstrate the long term performance potential of any photovoltaic technology, irrespective of its operating conditions and working environment, the power output of the CPV and PV system is given as Electrical Rating in $\mathrm{kWh} \mathrm{m}^{-2}$ year ${ }^{-1}$. Electrical rating gives the total energy output of a system for a particular period of testing. Based upon the long term electrical rating, the average efficiency of CPV system for total received DNI is given by equation (12).

$$
\eta_{\text {avg }}=\frac{\text { Electrical Rating }}{\text { Solar Input }}=\frac{\left[\left(\sum_{i=1}^{t}\left(\frac{\left(V_{C P V} \cdot I_{C P V}\right)_{i}-\left(V_{C P V} \cdot I_{C P V}\right)_{i-1}}{2 \times A_{C}}\right) \cdot S\right) \times \frac{365}{m}\right]}{\left[\left(\sum_{i=1}^{t}\left(\frac{(I r)_{i}-(I r)_{i-1}}{2}\right) . S\right) \times \frac{365}{m}\right]}
$$

Where $\mathrm{m}$ is the no. of days for the testing period and $\mathrm{S}$ is the scanning internal, which is set as 1second for current analysis. 


\section{Results and Discussion}

262

263

264

265

266

267

268

269

270

271

272

273

274

275

276

277

278

279

280

281

282

283

284

285

286

287

288

289

290

291

292

293

294

295

296

297

298

299

To theoretically analyze the performance of multi-junction solar cell (MJC), the variation of cell efficiency against concentration at cell area, at different cell temperatures, is given in Fig. 5. The simulated data is obtained from the performance characteristics model of InGaP/InGaAs/Ge MJC, as given by equations (10) and (11). On the other hand, the experimental data was recorded with confidence level of $96 \%$ and uncertainty value of $\pm 0.8 \%$ and the single point of experimental data is the average value of five different experiments repeated under similar conditions. However, the simulated performance data is within $\pm 2 \%$ range of the experimental data, showing perfect agreement for the complete range of operation parameters. The presented data shows that there is almost a steady decreasing effect of temperature on the cell efficiency. On the other hand, the cell efficiency is almost steady for higher concentrations, but has an increasing trend at the lower cell concentrations. In the real field conditions, both cell temperature and concentration change throughout the day. Although higher concentration can lead to higher cell efficiency, however, it can also increase the cell temperature due to increased amount of radiations and heat loss at the cell area. Such trend will be explained in the CPV-Hydrogen full day performance curves, shown in Fig. 6.

In order to analyze the developed CPV-hydrogen system, the performance curves of each of the component for whole day field operation, are shown in Fig. 6. The CPV system showed maximum efficiency of $28 \%$ for sunlight to electricity production only. On the other hand, maximum efficiency of $18 \%$ was recorded for sunlight to hydrogen conversion, around 9:15am, which is even higher than the electricity production efficiency of conventional PV systems. At that moment, it can be seen that the electrolyser efficiency is around $68 \%$ as per Eq. (8), as explained in the testing methodology section. On the other hand, the CPV is operating with efficiency of $27 \%$ which gives overall STH efficiency around 18\%, as per Eq. (9) which is based upon multiplication of CPV and electrolyser efficiencies. From the performance graph, it can also be seen that there is a slight drop in the efficiency of the CPV system, despite increase in the direct normal irradiance (DNI). This drop is due to increase in the heat sink temperature and consequently increase in the cell temperature at higher irradiance. As presented in Fig. 5 that the cell efficiency is increasing with increase in the concentration at the cell area. Therefore, the CPV efficiency must increase with DNI, but in actual, the trend is opposite. On the other hand, we can see in Fig. 5 that the cell efficiency is decreasing with increase in the cell temperature. Such temperature and efficiency trend can explain the behavior of decreasing CPV efficiency with increase in DNI, as the heat sink temperature is also increasing. With increase in DNI, the amount of solar radiation at the cell area also increase. As there is no significant improvement in the cell efficiency at higher efficiency, Fig. 5. Therefore, with increase in amount of solar radiation, the loss of radiations in form of heat, also increase. This loss of heat increases the cell temperature and as a result, the heat sink temperature also increase, which can be seen in Fig. 6. This increase in cell temperature lowers the efficiency of the cell and so as the CPV. That is why, we can see a decreasing trend with increase in DNI, which is due to increase in heat sink or cell temperature. The solar to hydrogen 
(STH) efficiency is also following similar decreasing trend. However, the main reason for STH efficiency drop is due to drop in the electrolyser efficiency. It must be noted that, as explained by equation (8), the efficiency of the electrolyser is only depending upon its operating voltage as its Faraday efficiency is recorded as $100 \%$. Therefore, with increase in the DNI, the power output from the CPV system increases and so as the power supplied to the electrolyser. Consequently, it's operating voltage also increase, causing decrease in the electrolyser efficiency. However, at the end of the day, the electrolyser efficiency is increasing again when DNI start to decrease. It is important to mention here the uncertainty of the reported experiment data for CPV-Hydrogen system. The current and voltage output from the CPV system, were measured with confidence level of $96 \%$ and $97 \%$, respectively, with corresponding uncertainty of $\pm 0.49 \%$ and $\pm 0.46 \%$, respectively. In addition, the measurements for direct normal irradiance (DNI) value have uncertainty of $\pm 1 \%$ with $96 \%$ confidence level. As a result of such measurement, the overall STH have uncertainty of $\pm 3.49 \%$ and the electrolyser and CPV efficiencies have $\pm 1.82 \%$ and $\pm 1.67 \%$ uncertainties, respectively.

It can be seen that the overall system efficiency is not steady during the whole day operation as it is affected by various performance parameters and operating factors. On the other hand, as a hydrogen production system, the main parameter point of interest is the amount of the hydrogen produced by the system at the end of the day. This production depends upon the amount of solar radiations received for that particular. However, the amount of solar radiations received is of serious concern in the tropical region where the test is being carried out. Therefore, the maximum efficiency is not an only and suitable parameter to present the actual performance of the solar energy system. In order to analyze the performance of the developed CPV-Hydrogen system under different weather conditions i.e. clear sky, partial cloudy and cloudy, the system performance was investigated for different days, with whole day operation. The long term performance of CPVHydrogen system is shown in Fig. 7.

From Fig. 7. It can be seen that the average solar to hydrogen efficiency of $14.5-16 \%$ was recorded for the whole day operation, which is decreasing with increase in the total amount of radiations received. Similar trend can be seen for the electrolyser efficiency which is the main reason for this overall decreasing efficiency trend, as explained and linked to its operating voltage, in the previous paragraph. However, the hydrogen production rating for electrolyser was recorded in the range 47.5-50 $\mathrm{kWh} \mathrm{kg}^{-1}$, which is increasing with decrease in the electrolyser efficiency. The significance of these average performance parameter is in the system design to accurately predict its capacity according to the hydrogen production demand, instead of deciding upon the maximum efficiency of the system. It must be noted that the measurement for hydrogen gas flow were taken with confidence level of $96 \%$ and uncertainty of $\pm 0.97 \%$. Hence, an uncertainty of $\pm 1.39 \%$ is recorded in the Faraday efficiency measurements.

As mentioned in the introduction section that the main application scope for the CPV system is considered to be the desert region, due to their clear sky conditions and high beam radiations availability as concentrators can only respond to the beam radiations. Therefore, despite higher 
efficiency, the main requirement from energy production system is the total amount of energy produced. Therefore, in order to analyze the production potential of CPV system for tropical and urban region, the developed CPV system was operated for one year operation in Singapore. The CPV system output in terms of $\mathrm{kWh} \mathrm{m}^{-2}$ of energy produced per year is shown in Fig. 8, and compared with the output of other conventional PV systems, installed in Singapore [31]. It can be seen that the CPV system offered 2-3 times higher output $\left(240.2 \mathrm{kWh} \mathrm{m}^{-2}\right.$ year $\left.{ }^{-1}\right)$ than the conventional PV systems, even under the tropical weather conditions of Singapore with $66 \%$ beam radiations availability. In addition, system also showed annual average efficiency of $22 \%$ based upon the total DNI received during one year operation. As the efficiency of PV system depends upon the global horizontal irradiance (GHI), instead of DNI due to their capability to accept both beam and diffuse radiations, therefore, the annual efficiency comparison of CPV and PV systems based upon the received GHI, also shown in Fig. 8. It can be seen that the CPV still can operate with two time higher efficiency than the conventional PV, in the tropical and the urban region. Based upon the annual average performances of CPV, PV and the daily average performance of the electrolyser, the annual average performance of solar to hydrogen production is predicted in Fig. 8. It can be seen that there is a potential of $5.11 \mathrm{~kg} \mathrm{~m}^{-2}$ year $^{-1}$ hydrogen production by the compact CPV system, making it a potential and sustainable solar energy system to operate in urban region for rooftop applications. In addition to the reported uncertainties in the DNI data and current/voltage measurements of CPV, it is also important to mention the uncertainty of GHI measurement i.e. $\pm 0.91 \%$ with confidence level of $95 \%$. Therefore, the uncertainties of $\pm 1.15 \%$, $\pm 0.88 \%$ and $\pm 1.26 \%$ can be reported in the data values of DNI efficiency, Electrical rating and GHI efficiency, respectively.

By considering the annual solar energy potential of $2400 \mathrm{kWh} \mathrm{m}^{-2}$ year $^{-1}$ for desert region of Saudi Arabia [53], with $80 \%$ beam radiations availability, the average annual performance of CPV/PV and CPV/PV-Hydrogen systems for such region is also given in Fig. 8. It can be seen that with average efficiency of $22 \%$, the power production potential of CPV system can be predicted as $422.4 \mathrm{kWh} \mathrm{m}^{-2}$ year $^{-1}$ for desert region. On the other hand, PV system showed maximum production potential of $180.3 \mathrm{kWh} \mathrm{m}^{-2}$ year $^{-1}$, which is still about $30 \%$ less than the CPV production in tropical region. Similarly, the overall hydrogen production potential of CPVhydrogen system operated in tropical region is also higher than that of PV operated in desert region. The CPV-Hydrogen system can offer hydrogen production potential as high as $9.0 \mathrm{~kg} \mathrm{~m}^{-2} \mathrm{year}^{-1}$ with $15 \%$ average system efficiency under desert condition. Therefore, with such high potential of CPV at all levels of operating conditions, it can be a sustainable and game changer solar energy system in form of compact CPV-hydrogen system, in current photovoltaic market of conventional $\mathrm{PV}$, which has the capability to be a primary and steady energy source by replacing conventional power plants.

\section{Conclusion}

A compact and cost effective design of CPV system, has been proposed to eradicate the limitations associated with the conventional gigantic CPV system design. The proposed system is successfully 
developed and tested for rooftop application in the tropical region of Singapore. The master slave configuration proposes a cost effective control for solar trackers of compact CPV field, with reduced hardware requirement than the conventional CPV field design. In addition, a low cost but highly accurate and sensitive solar tracking sensor design is proposed, developed and tested for CPV application with tracking accuracy as high as $0.1^{\circ}$.

As a sustainable power source with steady power supply, the compact CPV-hydrogen system is developed and tested for rooftop application in tropical weather conditions of Singapore. The system showed electrical efficiency as high as $28 \%$ and STH efficiency of $18 \%$. The CPV and CPV-hydrogen systems showed long term performance of $240.2 \mathrm{kWh} \mathrm{m}^{-2}$ year $^{-1}$ and $5.11 \mathrm{~kg} \mathrm{~m}^{-2}$ year $^{-1}$, for tropical regions and $422.4 \mathrm{kWh} \mathrm{m}^{-2}$ year $^{-1}$ and $9.0 \mathrm{~kg} \mathrm{~m}^{-2}$ year ${ }^{-1}$ for desert regions respectively. In addition, the CPV system showed 2-3 times higher energy output than the conventional PV, even in tropical region. On the other hand, CPV and CPV-hydrogen system both, operated under tropical conditions, showed 30-40\% better performance even when compared with the performance of conventional PV operated in desert conditions. Such a compact CPV system approach, with superior performance at all levels as compared to conventional PV, will increase the market trend of CPV system which will be available to each level of customers. In addition, such photovoltaic system with pave the way for high efficiency solar to hydrogen production, for a sustainable and potential solar energy system with high energy density, zero intermittency and smaller footprint, irrespective of operating and environmental conditions.

\section{Acknowledgement}

This research was supported by the International Research Scholarship of Mechanical Engineering Department, National University of Singapore and collaborated with King Abdullah University of Science and Technology.

\section{Nomenclature}

\begin{tabular}{|c|c|c|c|}
\hline $\mathrm{I}_{\mathrm{E}}$ & Electrolyser Current (A) & $\mathrm{CPV}$ & Concentrated Photovoltaic \\
\hline$\omega$ & Hour angle (degree) & GHI & Global horizontal irradiance \\
\hline $\mathrm{d}$ & $\begin{array}{l}\text { Distance between photo-sensors } \\
(\mathrm{mm})\end{array}$ & $\mathrm{h}$ & $\begin{array}{l}\text { Distance between collimator and } \\
\text { photo-sensor array }(\mathrm{mm})\end{array}$ \\
\hline PEM & Proton Exchange Membrane & $\delta$ & Declination angle (degree) \\
\hline $\mathrm{ADC}$ & Analogue to Digital Converter & $\theta_{\mathrm{z}}$ & Zenith angle (degree) \\
\hline DNI & Direct Normal Irradiance, $\left(\mathrm{W} / \mathrm{m}^{2}\right)$ & $\mathrm{A}_{\text {con }}$ & Area of Solar Concentrator $\left(\mathrm{m}^{2}\right)$ \\
\hline PSD & Position Sensitive Diode & $b_{t}$ & Collimated beam thickness (mm) \\
\hline STH & Sunlight to Hydrogen & $\theta_{\mathrm{a}}$ & Azimuth angle (degree) \\
\hline Ir & Irradiance, $\left(\mathrm{W} / \mathrm{m}^{2}\right)$ & RTC & Real Time Clock \\
\hline PV & Photovoltaic & $\mathrm{S}$ & $\begin{array}{l}\text { Distance between collimating } \\
\text { lenses }(\mathrm{mm})\end{array}$ \\
\hline $\mathrm{f}_{\mathrm{cx}}$ & Focal length of convex lens (mm) & $\mathrm{f}_{\mathrm{cn}}$ & Focal length of concave lens (mm) \\
\hline $\mathrm{D}_{\mathrm{cx}}$ & Convex lens diameter $(\mathrm{mm})$ & $\mathrm{V}_{\mathrm{CPV}}$ & CPV Voltage (V) \\
\hline
\end{tabular}




\begin{tabular}{|c|c|c|c|}
\hline$\varnothing$ & Latitude (degree) & CTS & Colour Tracking Sensor \\
\hline $\mathrm{N}_{\mathrm{EC}}$ & Number of Cells of Electrolyser & $\mathrm{F}$ & Faraday Constant (A.s/mol) \\
\hline$\eta_{\mathrm{EF}}$ & $\begin{array}{l}\text { Faraday Efficiency of Electrolyser } \\
(\%)\end{array}$ & $\eta_{\mathrm{EL}}$ & Electrolyser Efficiency (\%) \\
\hline$\eta_{\text {avg }}$ & $\begin{array}{l}\text { Long Term average solar } \\
\text { efficiency }(\%)\end{array}$ & $\mathrm{I}_{\mathrm{E}}$ & Electrolyser Current (A) \\
\hline$\eta_{\mathrm{CPV}}$ & CPV Efficiency $(\%)$ & $P_{\mathrm{CPV}}$ & CPV Power Output (W) \\
\hline $\mathrm{U}_{\mathrm{E}}$ & Electrolyser Cell Voltage (V) & $\mathrm{n}_{\mathrm{E}}$ & $\begin{array}{l}\text { Electrons Requirement for Water } \\
\text { Splitting }\end{array}$ \\
\hline$\dot{n}_{E, H 2}$ & $\begin{array}{l}\text { Hydrogen Production Flow Rate } \\
\text { from Electrolyser }(\mathrm{mol} / \mathrm{s})\end{array}$ & $\mathrm{V}_{\text {OC }}$ & $\begin{array}{l}\text { Solar Cell Open Circuit Voltage } \\
\text { (V) }\end{array}$ \\
\hline $\mathrm{I}_{\mathrm{CPV}}$ & CPV Current (A) & $\mathrm{MJC}$ & Multi-junction solar cell \\
\hline MPPT & Maximum Power Point Tracking & GPS & Global positioning system \\
\hline $\mathrm{D}_{\mathrm{cx}}$ & Convex lens diameter $(\mathrm{mm})$ & $\mathrm{L}_{\mathrm{m}}$ & $\begin{array}{l}\text { Maximum Depth of ZigBee } \\
\text { Network }\end{array}$ \\
\hline $\mathrm{R}_{\mathrm{m}}$ & $\begin{array}{l}\text { Maximum number of routing } \\
\text { cable children }\end{array}$ & $\mathrm{C}_{\mathrm{m}}$ & $\begin{array}{l}\text { Maximum number of non-routing } \\
\text { cable children }\end{array}$ \\
\hline $\mathrm{I}_{\mathrm{C}}$ & Solar Cell Current (A) & $\mathrm{C}$ & Coordinator \\
\hline ED & End Device & $\mathrm{R}$ & Router \\
\hline q & Elementary charge (Coulomb) & $\mathrm{k}$ & Boltzman's Constant $\left(\mathrm{m}^{2} \mathrm{kgs}^{-2} \mathrm{~K}^{-1}\right)$ \\
\hline $\mathrm{n}_{\mathrm{C}}$ & $\begin{array}{l}\text { Diode ideality factor for } \\
\text { concentrated solar cell }\end{array}$ & DNI & Direct Normal Irradiance \\
\hline$\eta_{F}$ & $\begin{array}{l}\text { Optical Efficiency of Fresnel Lens } \\
(\%)\end{array}$ & $\eta_{\mathrm{MR}}$ & $\begin{array}{l}\text { Reflectance Efficiency of optical } \\
\text { material }(\%)\end{array}$ \\
\hline$\eta_{\mathrm{H}}$ & $\begin{array}{l}\text { Optical Efficiency of } \\
\text { Homogeniser }(\%)\end{array}$ & $\mathrm{a}$ & Fitting parameter \\
\hline$\eta_{\mathrm{MT}}$ & $\begin{array}{l}\text { Transmission Efficiency of optical } \\
\text { material }(\%)\end{array}$ & $\eta_{\mathrm{AL}}$ & $\begin{array}{l}\text { Optical Efficiency related to } \\
\text { Aperture Loss of Fresnel Lens }(\%)\end{array}$ \\
\hline$\eta_{\mathrm{CT}}$ & $\begin{array}{l}\text { Transmission Efficiency of optical } \\
\text { material of glass cover plate }(\%)\end{array}$ & $\eta_{\mathrm{ac}}$ & $\begin{array}{l}\text { Optical Efficiency related to } \\
\text { acceptance angle and tracking error }\end{array}$ \\
\hline$\theta_{\mathrm{te}}$ & $\begin{array}{l}\text { Tracking error of Solar Tracker } \\
\text { (degree) }\end{array}$ & $\theta_{\mathrm{ac}}$ & $\begin{array}{l}\text { Acceptance angle of concentrating } \\
\text { assembly (degree) }\end{array}$ \\
\hline$\theta_{\mathrm{ac}, \max }$ & $\begin{array}{l}\text { Maximum Acceptance angle of } \\
\text { concentrating assembly (degree) }\end{array}$ & $\mathrm{b}$ & Fitting parameter \\
\hline $\mathrm{I}_{\mathrm{b}}$ & $\begin{array}{l}\text { Direct Normal Irradiance (DNI), } \\
\left(\mathrm{W} / \mathrm{m}^{2}\right)\end{array}$ & $\mathrm{A}_{\text {con }}$ & Area of Solar Concentrator $\left(\mathrm{m}^{2}\right)$ \\
\hline $\mathrm{T}_{\mathrm{C}}$ & Solar Cell Temperature $\left({ }^{\circ} \mathrm{C}\right)$ & $\mathrm{P}_{\mathrm{C}}$ & Solar Cell Power $(\mathrm{W})$ \\
\hline $\mathrm{P}_{\mathrm{mppt}}$ & $\begin{array}{l}\text { Solar Cell Maximum Power Point } \\
\text { Power (W) }\end{array}$ & $\eta_{\mathrm{OP}}$ & $\begin{array}{l}\text { Optical Efficiency of Concentrating } \\
\text { Assembly }(\%)\end{array}$ \\
\hline$A_{C}$ & Solar cell Area $\left(\mathrm{m}^{2}\right)$ & $\mathrm{C}_{\mathrm{C}}$ & $\begin{array}{l}\text { Solar Concentration at Solar Cell } \\
\text { Area (Suns) }\end{array}$ \\
\hline $\mathrm{V}_{\mathrm{C}}$ & Solar Cell Voltage (V) & $\mathrm{I}_{\mathrm{SC}}$ & Solar Cell Short Circuit Current \\
\hline
\end{tabular}

(A) 


\section{References}

[1] Martinez S, Michaux G, Salagnac P, Bouvier JL. Micro-combined heat and power systems (micro-CHP) based on renewable energy sources. Energy Conversion and Management 2017, 154, $262-85$.

[2] Ali B, Kumar A. Development of water demand coefficients for power generation from renewable energy technologies. Energy Conversion and Management 2017, 143, 470-81.

[3] Ye B, Zhang K, Jiang J, Miao L, Li J. Towards a 90\% renewable energy future: A case study of an island in the South China Sea. Energy Conversion and Management 2017, 142, 28-41.

[4] Shen P, Lukes JR. Impact of global warming on performance of ground source heat pumps in US climate zones. Energy Conversion and Management 2015, 101, 632-43.

[5] Burhan M, Chua KJE, Ng KC. Simulation and development of a multi-leg homogeniser concentrating assembly for concentrated photovoltaic (CPV) system with electrical rating analysis. Energy Conversion and Management 2016, 116, 58-71.

[6] Castillo A, Gayme DF. Grid-scale energy storage applications in renewable energy integration: A survey. Energy Conversion and Management 2014, 87, 885-94.

[7] Al-Falahi MD, Jayasinghe SD, Enshaei H. A review on recent size optimization methodologies for standalone solar and wind hybrid renewable energy system. Energy Conversion and Management 2017, 143, 252-74.

[8] Ng KC, Burhan M, Shahzad MW, Ismail AB. A Universal Isotherm Model to Capture Adsorption Uptake and Energy Distribution of Porous Heterogeneous Surface. Scientific Reports 2017, 7(1), 10634.

[9] Burhan M, Chua KJE, Ng KC. Sunlight to hydrogen conversion: Design optimization and energy management of concentrated photovoltaic (CPV-Hydrogen) system using micro genetic algorithm. Energy 2016, 99, 115-128.

[10] Gude VG, Nirmalakhandan N. Sustainable desalination using solar energy. Energy Conversion and Management 2010, 51(11), 2245-51.

[11] Wang Y, Li M, Du W, Ji X, Xu L. Experimental investigation of a solar-powered adsorption refrigeration system with the enhancing desorption. Energy Conversion and Management 2018, $155,253-61$.

[12] Zhu Y, Zhai R, Zhao M, Yang Y, Yan Q. Evaluation methods of solar contribution in solar aided coal-fired power generation system. Energy Conversion and Management 2015, 102, 20916. 
[13] Ji W, Zhou Y, Sun Y, Zhang W, An B, Wang J. Thermodynamic analysis of a novel hybrid wind-solar-compressed air energy storage system. Energy Conversion and Management 2017, 142, 176-87.

[14] Peng WX, Wang LS, Mirzaee M, Ahmadi H, Esfahani MJ, Fremaux S. Hydrogen and syngas production by catalytic biomass gasification. Energy Conversion and Management 2017, 135, 270-3.

[15] González I, Calderón AJ, Andújar JM. Novel remote monitoring platform for RES-hydrogen based smart microgrid. Energy Conversion and Management 2017, 148, 489-505.

[16] Burhan M, Shahzad MW, Ng KC. Development of performance model and optimization strategy for standalone operation of CPV-hydrogen system utilizing multi-junction solar cell. International Journal of Hydrogen Energy 2017, http://dx.doi.org/ 10.1016/j.ijhydene.2017.08.186

[17] Al-Zareer M, Dincer I, Rosen MA. Development and assessment of a novel integrated nuclear plant for electricity and hydrogen production. Energy Conversion and Management 2017, 134, 221-34.

[18] Qin J, Hu E, Nathan GJ, Chen L. Concentrating or non-concentrating solar collectors for solar Aided Power Generation?. Energy Conversion and Management 2017, 152, 281-90.

[19] Burhan M, Chua KJE, Ng KC. Electrical rating of concentrated photovoltaic (CPV) systems: long-term performance analysis and comparison to conventional PV systems. International Journal of Technology 2016, 7(2), 189-196. DOI: 10.14716/ijtech.v7i2.2983.

[20] Bhattacharyya R, Misra A, Sandeep KC. Photovoltaic solar energy conversion for hydrogen production by alkaline water electrolysis: conceptual design and analysis. Energy Conversion and Management 2017, 133, 1-3.

[21] Burhan M, Chua KJE, Ng KC. Long term hydrogen production potential of concentrated photovoltaic (CPV) system in tropical weather of Singapore. International Journal of Hydrogen Energy 2016, 41(38), 16729-16742.

[22] Amirante R, Cassone E, Distaso E, Tamburrano P. Overview on recent developments in energy storage: mechanical, electrochemical and hydrogen technologies. Energy Conversion and Management 2017, 132, 372-87.

[23] Dufo-López R, Fernández-Jiménez LA, Ramírez-Rosado IJ, Artal-Sevil JS, DomínguezNavarro JA, Bernal-Agustín JL. Daily operation optimisation of hybrid stand-alone system by model predictive control considering ageing model. Energy Conversion and Management 2017, 134, 167-77.

[24] Burhan M, Oh SJ, Chua KJ, Ng KC. Solar to hydrogen: Compact and cost effective CPV field for rooftop operation and hydrogen production. Applied Energy 2017, 194, 255-66. 
470 [25] EVWorld. Energy content of fuels, http://www.evworld.com/library/energy_numbers.pdf. 471 Date retrieved: 20-12-2015.

472 [26] ForestBioEnergy. Sustainable forestry for bioenergy and biobased products. Energy basics.

473 Fact Sheet 5.8, http://www. forestbioenergy.net/training-materials/fact-sheets/module-5-fact474 sheets/fact-sheet-5-8-energy-basics. Date retrieved: 20-12-2015.

475 [27] Yingli Green Energy Holding Co. Ltd., PANDA 60 CELL SERIES 2, www.yinglisolar.com 476 [28] Yingli Green Energy Holding Co. Ltd., YGE 48 Cell 40mm SERIES, www.yinglisolar.com 477 [29] MiaSolé Hi-Tech Corp., FLEX-02N SERIES CIGS MODULE, www. miasole.com

478 [30] Burhan M, Oh SJ, Chua KJE, Ng KC. Double lens collimator solar feedback sensor and master 479 slave configuration: Development of compact and low cost two axis solar tracking system for CPV 480 applications. Solar Energy 2016, 137, 352-363.

481 [31] Lin-Heng L, Lok-Ming C, Chia A, Gunawansa A, Harn-Wei K. Sustainability Matters, 482 Challenges and Opportunities in Environmental Management in Asia. Pearson Education South 483 Asia Pte Ltd, 2011. Singapore.

484 [32] Khaselev O, Bansal A, Turner JA. High-efficiency integrated multijunction 485 photovoltaic/electrolysis systems for hydrogen production. International Journal of Hydrogen 486 Energy 2001, 26(2), 127-132.

487 [33] National Renewable Energy Laboratory $\quad$ (NREL). 488 http://www.nrel.gov/ncpv/images/efficiency_chart.jpg. Date retrieved: 01-08-2016.

489 [34] Philipps SP, Bett AW, Horowitz K, Kurtz S. CURRENT STATUS OF CONCENTRATOR 490 PHOTOVOLTAIC (CPV) TECHNOLOGY. Fraunhofer ISE, NREL. September, 2015. 491 https://www.ise.fraunhofer.de/en/publications/veroeffentlichungen-pdf-dateien-en/studien-und-

492 konzeptpapiere/current-status-of-concentrator-photovoltaic-cpv-technology.pdf, Date retrieved: 493 07-11-2017.

494 [35] Muhammad B, Seung JO, Ng KC, Chun W. Experimental Investigation of Multijunction Solar 495 Cell Using Two Axis Solar Tracker. In Applied Mechanics and Materials 2016 (Vol. 819, pp. 536496 540). Trans Tech Publications.

497 [36] Rajeshwar K, McConnell R, Licht S. Solar hydrogen generation. Toward a renewable energy 498 future. Springer: New York. 2008.

499 [37] Burhan M, Shahzad MW, Ng KC. Long-term performance potential of concentrated 500 photovoltaic (CPV) systems. Energy Conversion and Management 2017, 148, 90-9.

501 [38] International Energy Agency (IEA). Trends 2015 in Photovoltaic Applications, Survey Report 502 of Selected IEA Countries between 1992 and 2014. Report IEA-PVPS T1-27:2015. 
503 [39] McConnell R. A Solar Concentrator Pathway to Low-Cost Electrolytic Hydrogen. In Solar 504 Hydrogen Generation. Springer New York. 2008, (pp. 65-86).

505 [40] Roth P, Georgiev A, Boudinov H. Design and construction of a system for suntracking. 506 Renewable Energy 2004, 29(3), 393-402.

507 [41] Kim Y, Han GY, Seo T. An evaluation on thermal performance of CPC solar collector. 508 International Communications in Heat Mass Transfer 2008, 35(4), 446-457.

509 [42] Batayneh W, Owais A, Nairoukh M. An intelligent fuzzy based tracking controller for a dual510 axis solar PV system. Automation in Construction 2013, 29, 100-106.

511 [43] Mavromatakis F, Franghiadakis Y. A highly efficient novel azimuthal heliotrope. Solar 512 Energy 2008, 82(4), 336-342.

513 [44] Chin CS, Babu A, McBride W. Design, modeling and testing of a standalone single axis active 514 solar tracker using MATLAB/Simulink. Renewable Energy 2011, 36(11), 3075-3090.

515 [45] Luque-Heredia I, Moreno JM, Magalhaes PH, Cervantes R, Quemere G, Laurent O. Inspira's 516 CPV Sun Tracking. Concentrator Photovoltaics 2007, 130, 221.

517 [46] Yao Y, Hu Y, Gao S, Yang G, Du J. A multipurpose dual-axis solar tracker with two tracking 518 strategies. Renewable Energy 2014, 72, 88-98.

519 [47] Luque-Heredia I, Moreno JM, Magalhaes PH, Cervantes R, Quemere G, Laurent O. Inspira's 520 CPV Sun Tracking. Concentrator Photovoltaics 2007, 130, 221.

521 [48] Xu G, Zhong Z, Wang B, Guo R, Tian Y. Design of PSD based solar direction sensor. In Sixth 522 International Symposium on Precision Mechanical Measurements, International Society for 523 Optics and Photonics 2013, 89162-89162.

524 [49] Farahani S. ZigBee wireless networks and transceivers. newnes, 2011.

525 [50] Oh SJ, Burhan M, Ng KC, Kim Y, Chun W. Development and performance analysis of a two526 axis solar tracker for concentrated photovoltaics. International Journal of Energy Research 2015, 527 39(7), 965-76.

528 [51] Harrison KW, Remick R, Martin GD, Hoskin A. Hydrogen Production: Fundamentals and 529 Case Study Summaries. 18 ${ }^{\text {th }}$ World Energy Conference Essen, Germany. 2010.

530 [52] Burhan M, Shahzad MW, Choon NK. Hydrogen at the Rooftop: Compact CPV-Hydrogen 531 system to Convert Sunlight to Hydrogen. Applied Thermal Engineering 2018, 132, 154-164.

532 [53] Almarshoud AF. Performance of solar resources in Saudi Arabia. Renewable and Sustainable 533 Energy Reviews 2016, 66, 694-701. 


\section{$534 \quad$ List of Table Captions:}

535 Table 1: Temperature characteristics of triple junction $\mathrm{InGaP} / \mathrm{InGaAs} / \mathrm{Ge}$ solar cell 


\section{$536 \quad$ List of Figure Captions:}

537 Figure 1: Master Slave Configuration for Cost Effective CPV Field Control

538 Figure 2: Proposed design of Double Lens Collimator Solar Tracking Sensor

539 Figure 3: (a) Prototype and (b) Flow Schematic of Compact CPV-Hydrogen System

540 Figure 4: Proposed hybrid Tracking Algorithm for Compact CPV

541 Figure 5: experimental and simulated data of InGaP/InGaAs/Ge based MJC

542 Figure 6: Field Performance Curves of CPV Hydrogen System

543 Figure 7: Average Daily Performance for CPV Hydrogen System in Tropical Region

544 Figure 8: Annual Average Output of CPV and CPV-Hydrogen System in Tropical Region 
545 Table 1: Temperature characteristics of triple junction $\mathrm{InGaP} / \mathrm{InGaAs} / \mathrm{Ge}$ solar cell

\begin{tabular}{|c|c|c|c|c|c|}
\hline Parameter & $\mathrm{x} 500$ & $\mathrm{x} 300$ & $\mathrm{x} 150$ & $\mathrm{x} 100$ & $\mathrm{x} 50$ \\
\hline $\mathrm{dI}_{\mathrm{sc}} / \mathrm{dT}_{\mathrm{C}}$ & 3.9644 & 2.3756 & 1.1889 & 0.7756 & 0.3867 \\
\hline $\mathrm{dV}_{\mathrm{OC}} / \mathrm{dT}_{\mathrm{C}}$ & -0.00424 & -0.00432 & -0.00456 & -0.00462 & -0.00481 \\
\hline
\end{tabular}

546 

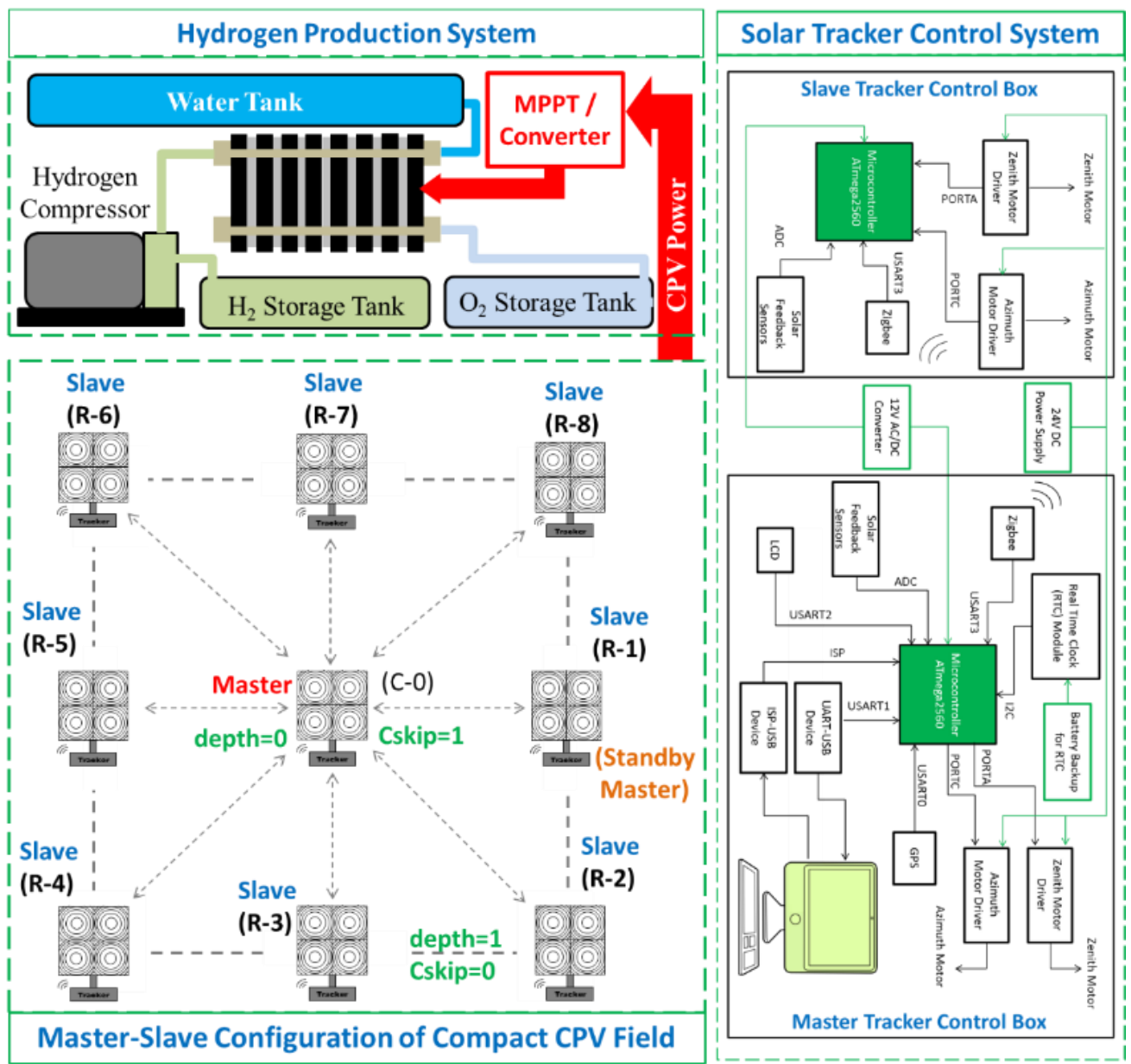

Figure 1: Master Slave Configuration for Cost Effective CPV Field Control 


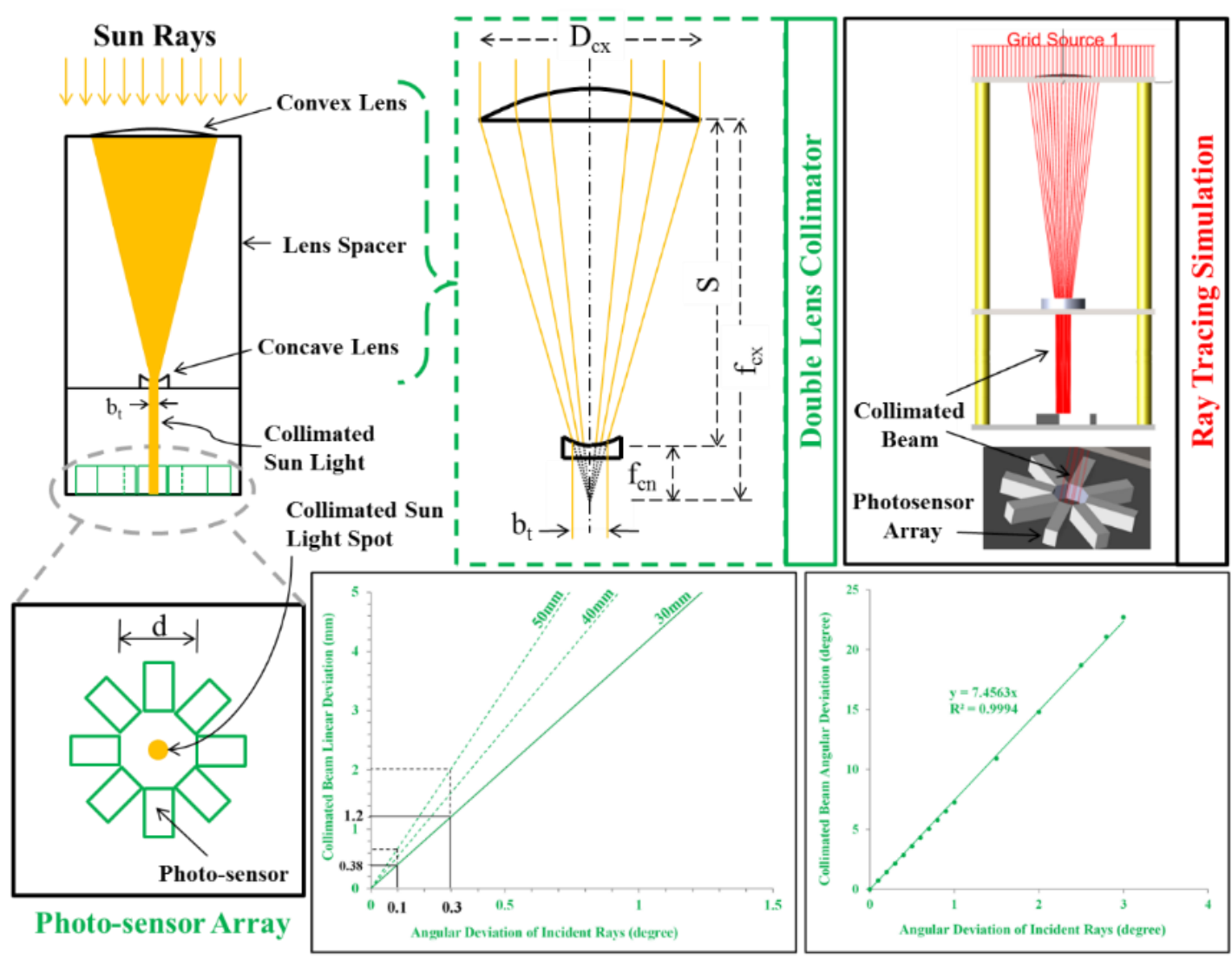




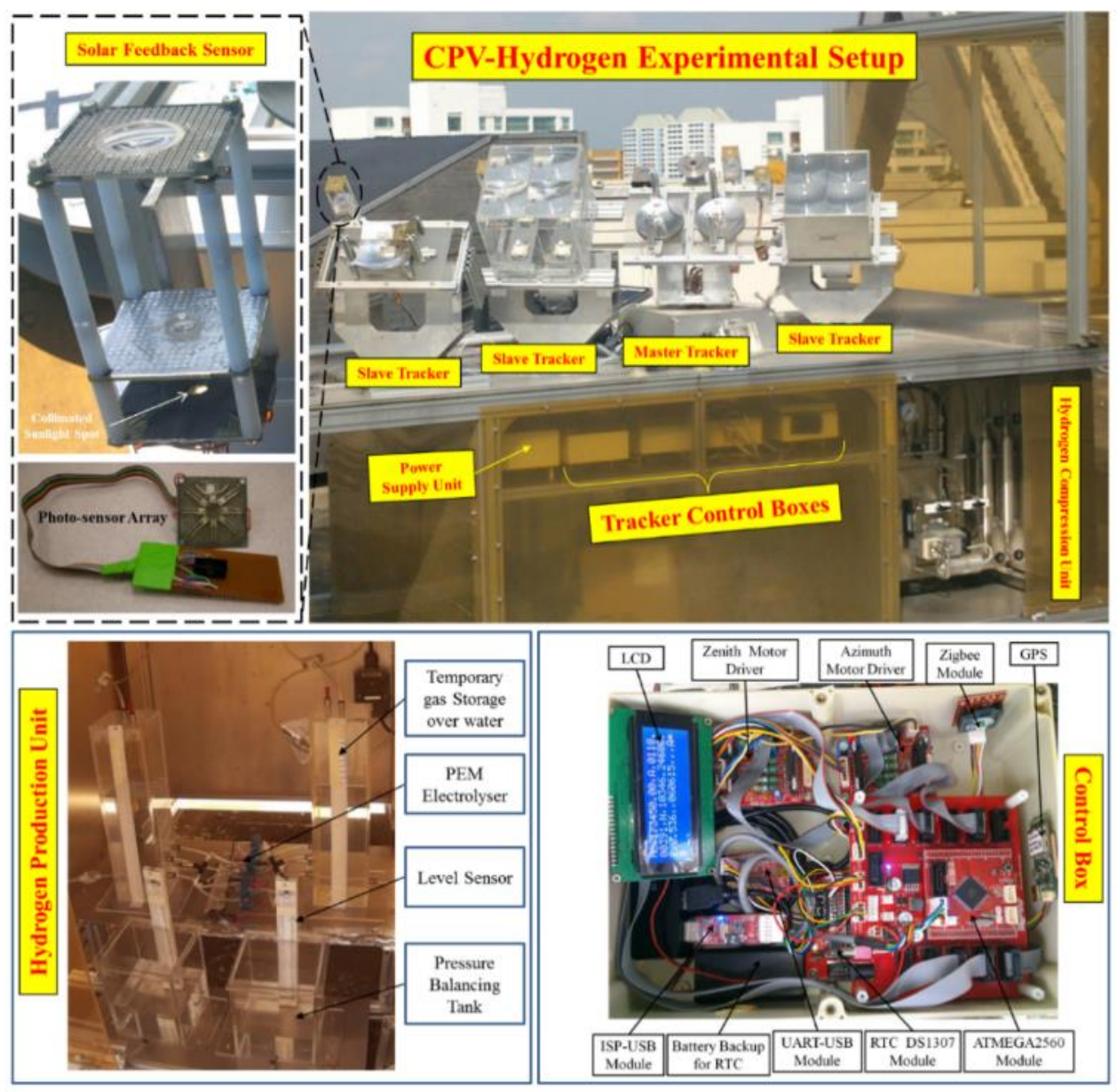

(a)

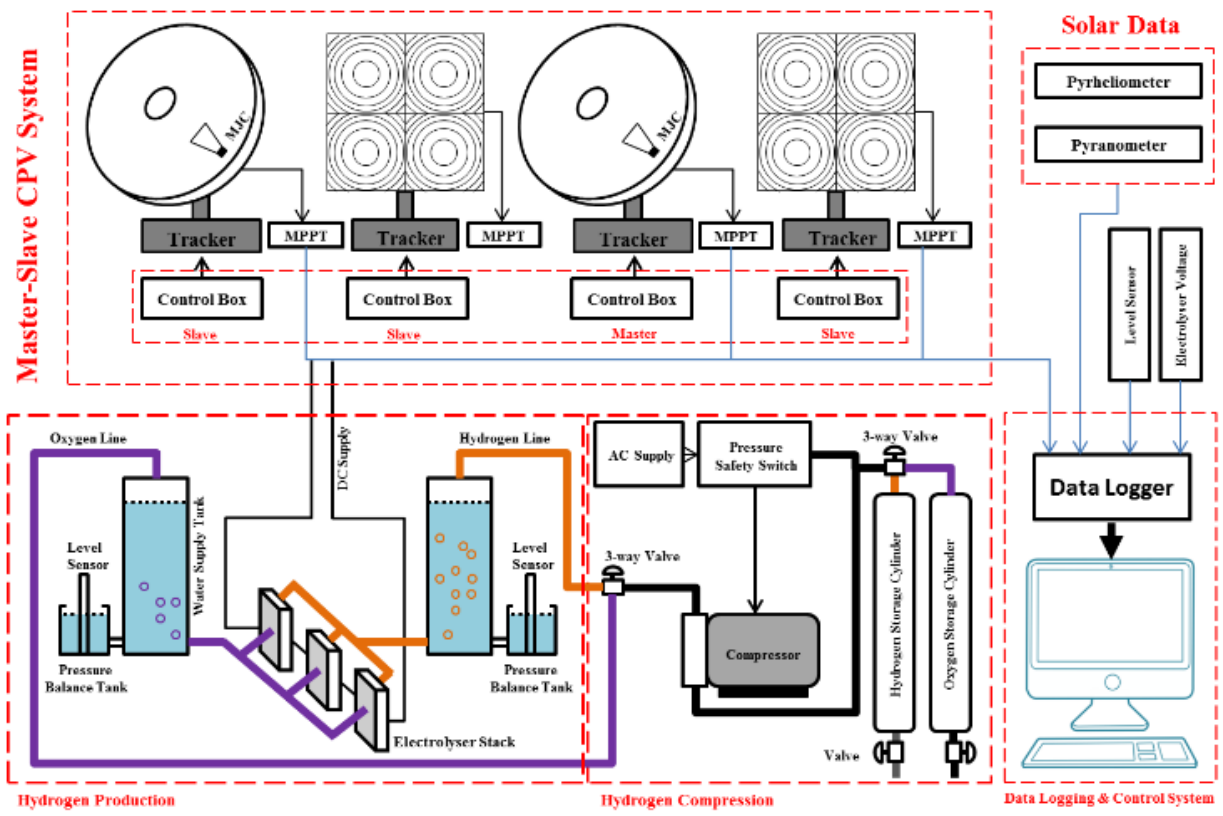

(b)

Figure 3: (a) Prototype and (b) Flow Schematic of Compact CPV-Hydrogen System 


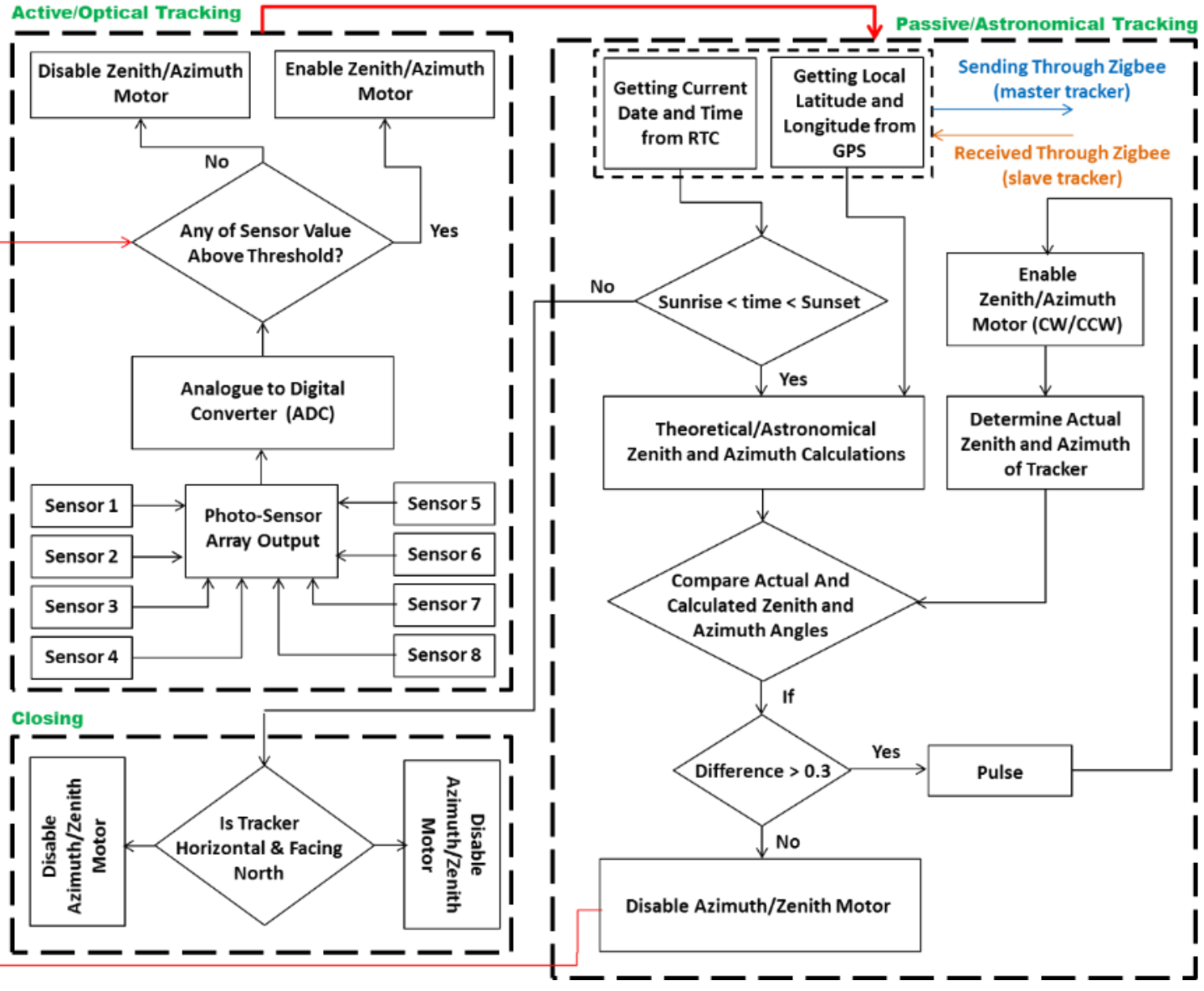

$\underline{\text { Figure 4: Proposed hybrid Tracking Algorithm for Compact CPV }}$ 


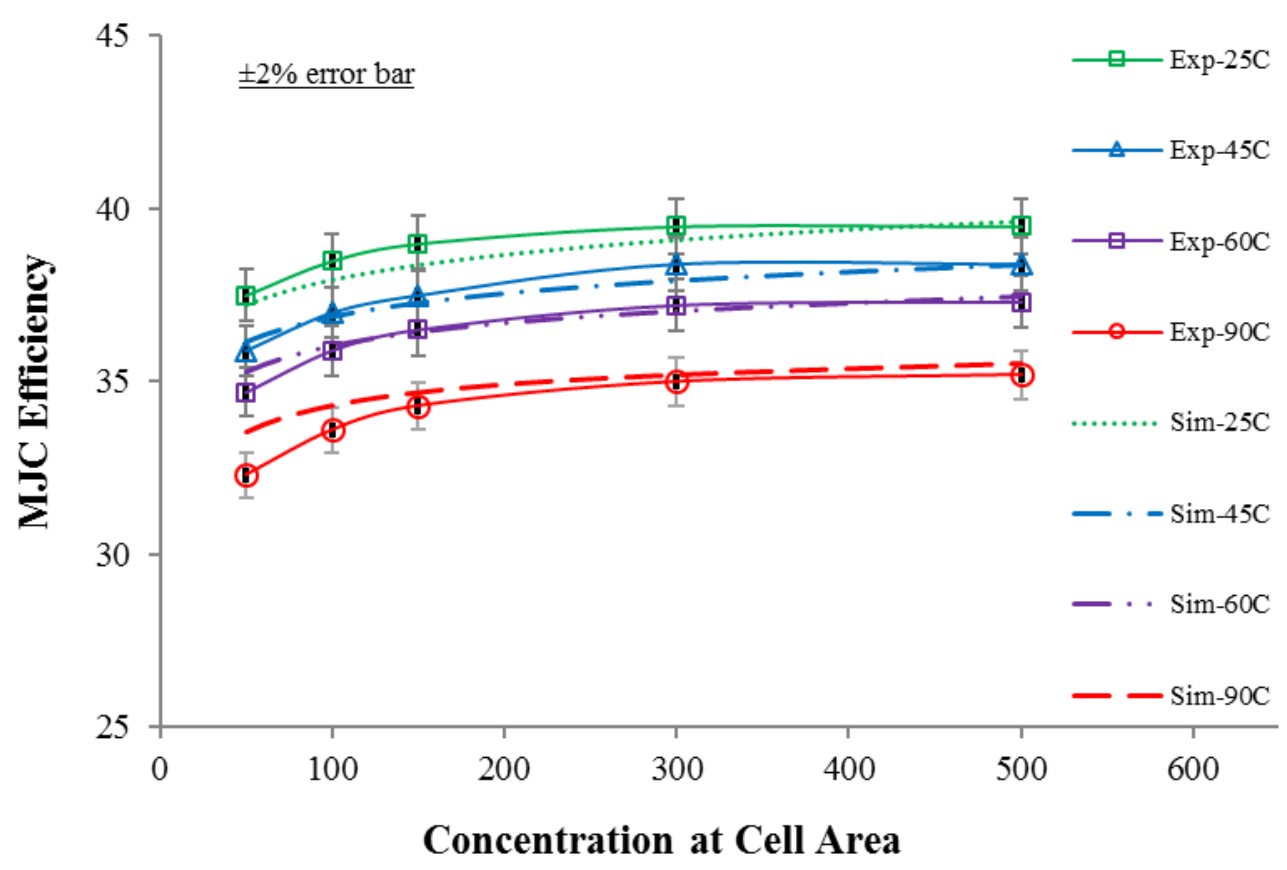

Figure 5: experimental and simulated data of InGaP/InGaAs/Ge based MJC 


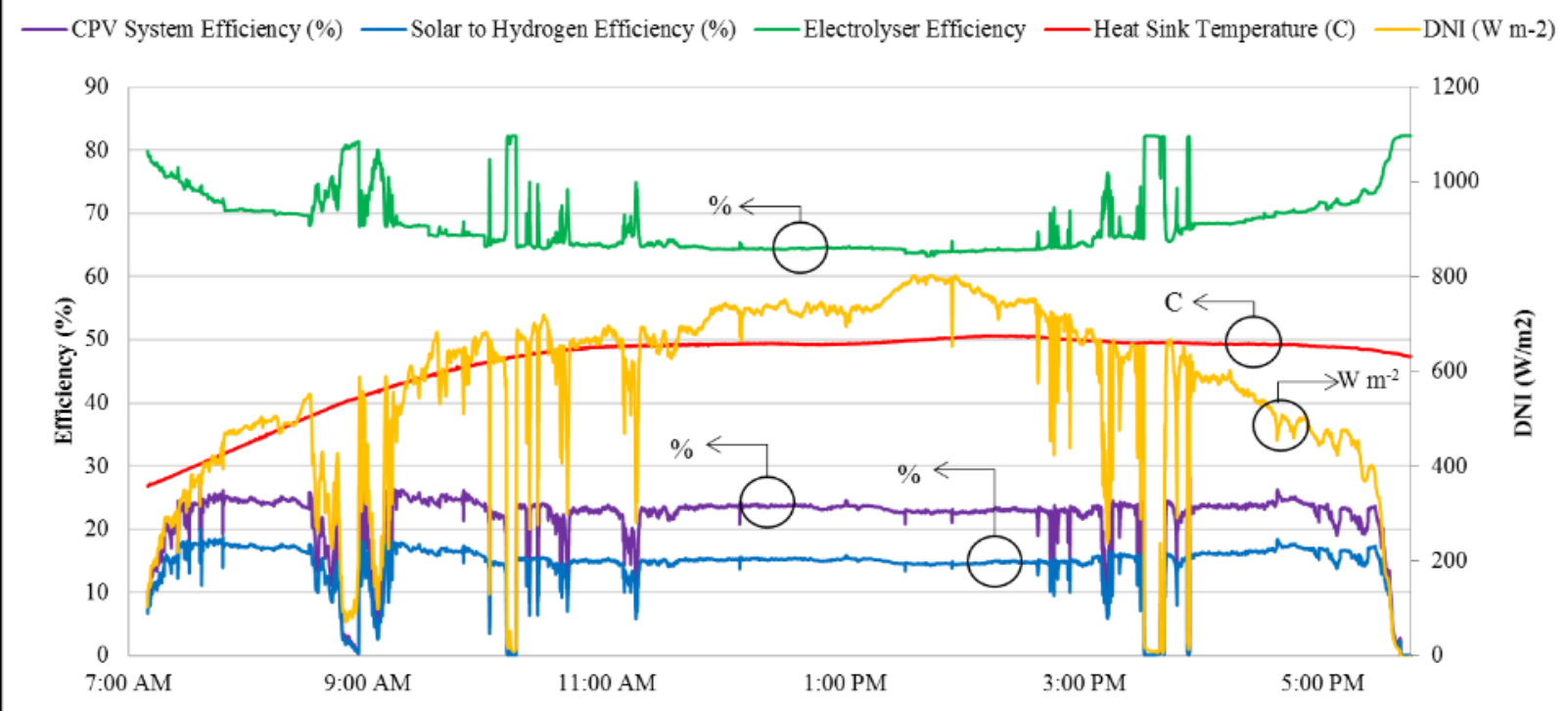




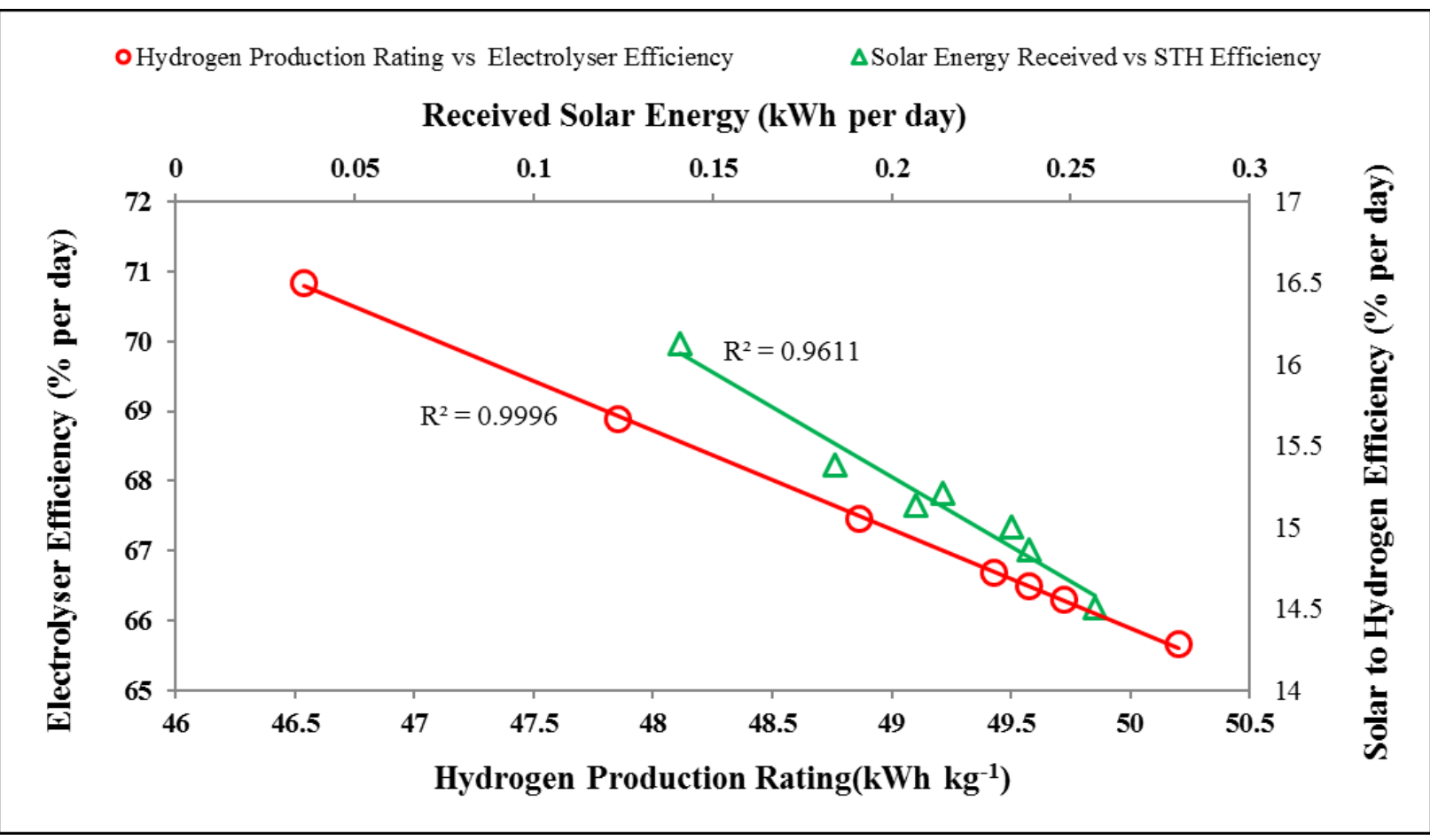

Figure 7: Average Daily Performance for CPV Hydrogen System in Tropical Region 


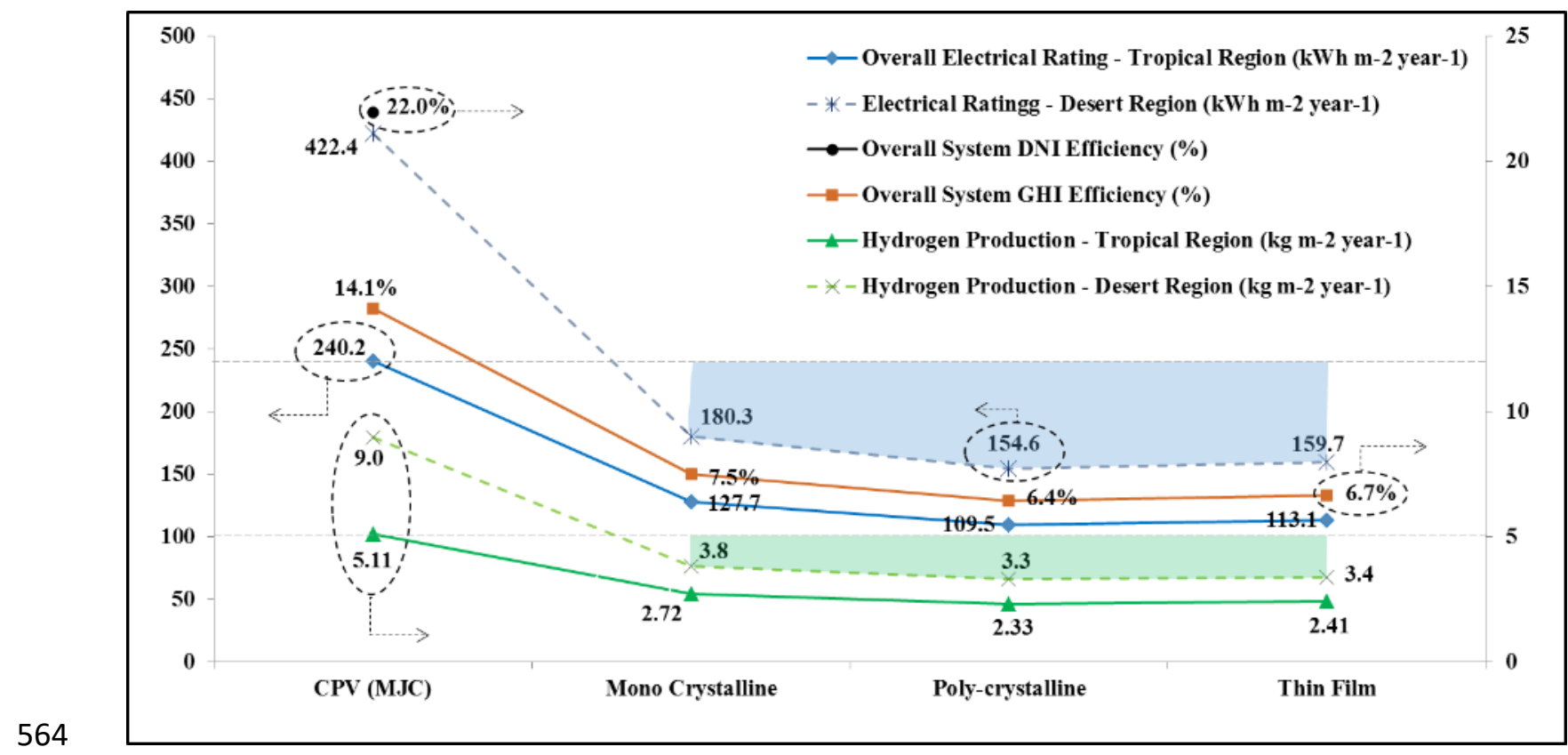

$565 \quad$ Figure 8: Annual Average Output of CPV and CPV-Hydrogen System in Tropical Region 